\title{
Long-term results following titanium cranioplasty of large skull defects
}

\author{
Mario Cabraja, M.D., ${ }^{1}$ Martin Klein, M.D., ${ }^{2}$ and Thomas-Nikolas Lehmann, M.D. ${ }^{1}$ \\ Departments of ${ }^{I}$ Neurosurgery and ${ }^{2}$ Maxillofacial Surgery, Clinical Navigation and Robotics, \\ Charité-Universitätsmedizin Berlin, Germany
}

\begin{abstract}
Object. Decompressive craniectomy is an established procedure to lower intracranial pressure. Therefore, cranioplasty remains a necessity in neurosurgery as well. If the patient's own bone flap is not available, the surgeon can choose between various alloplast grafts. A review of the literature proves that $4-13.8 \%$ of polymethylmethacrylate plates and 2.6-10\% of hydroxyapatite-based implants require replacement. In this retrospective study of large skull defects, the authors compared computer-assisted design/computer-assisted modeled (CAD/CAM) titanium implants for cranioplasty with other frequently used materials described in literature.

Methods. Twenty-six patients underwent cranioplasty with CAD/CAM titanium implants (mean diameter 112 $\mathrm{mm}$ ). With the aid of visual analog scales, the patients' pain and cosmesis were evaluated 6-12 years (mean 8.1 years) after insertion of the implants.

Results. None of the implants had to be removed. Of all patients, 68\% declared their outcomes as excellent, 24\% as good, $0.8 \%$ as fair, and $0 \%$ as poor. There was no resulting pain in $84 \%$ of the patients, and $88 \%$ were satisfied with the cosmetic result, noting $>75 \mathrm{~mm}$ on the visual analog scale of cosmesis. All patients would have chosen cranioplasty again, stating an improvement in their quality of life by the calvarial reconstruction. Nevertheless, follow-up images obtained in 4 patients undergoing removal of meningiomas was only suboptimal.

Conclusions. With the aid of CAD technology, all currently used alloplastic materials are suited even for large skull defect cranioplasty. Analysis of the authors' data and the literature shows that cranioplasty with CAD/CAM titanium implants provides the lowest rate of complications, reasonable costs, and acceptable postoperative imaging. Polymethylmethacrylate is suited for primary cranioplasty or for long-term follow-up imaging of tumors. Titanium implants seem to be the material of choice for secondary cranioplasty of large skull defects resulting from decompressive craniectomy after trauma or infarction. Expensive HA-based ceramics show no obvious advantage over titanium or PMMA. (DOI: 10.3171/2009.3.FOCUS091)
\end{abstract}

KEY WORDS - craniectomy • decompressive surgery - calvarial reconstruction

$\mathrm{D}$ ESPITE being in use for a long time, decompressive craniectomy remains an established procedure to lower intracranial pressure due to malignant brain swelling, ${ }^{19,30}$ and it is still undergoing technical improvements. ${ }^{32}$ Therefore, cranioplasty will remain a necessity in neurosurgery as well.

The surgical correction of skull defects has 2 main purposes: protection of the brain and a satisfying cosmetic result. The implanted material has to be durable and provide a low repulsion rate by the host. ${ }^{14}$ Because of immunological compatibility, the reimplantation of the patient's own bone flap is usually the treatment of choice. Nevertheless, age, difficulties with storage, tim-

\footnotetext{
Abbreviations used in this paper: $\mathrm{CAD}=$ computer-assisted design; $\mathrm{CAM}=$ computer-assisted modeled; $\mathrm{CFRP}=$ carbon fiber reinforced polymer; HA = hydroxyapatite; PMMA = polymethylmethacrylate; VASC $=$ visual analog scale for cosmesis; VASPI = VAS for pain intensity.
}

ing of surgery, and anatomical conditions can lead to the loss of the bone flap in a large number of cases. ${ }^{16,28}$ Various techniques are currently being discussed to rescue infected bone flaps or improve their preservability, ${ }^{1,4,20,24}$ but as of yet none of these offers results superior to the ones achievable with nonbioresorbable materials. Recent developments are looking toward osteoconductive bioresorbable materials, tissue engineering, $, 36,37,40,41$ osteoinduction by growth factors, and gene therapy, ${ }^{12,17,31}$ but despite promising experimental results in animals and preliminary studies, these new technologies still have to prove their worth in large-scale long-term clinical settings.

Until then the surgeon has the choice between various cranioplasty techniques. Computer-assisted design and modeling of cranioplastic materials has improved the cosmetic outcome as well as minimized the procedure

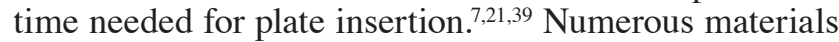
have shown high biocompatibility and clinical reliability, ${ }^{32}$ such as PMMA, titanium, numerous ceramics such as HA, carbon materials such as CFRP, and others (Table 
M. Cabraja, M. Klein, and T.-N. Lehmann

TABLE 1: Review of the literature regarding clinical studies dealing with alloplast graft cranioplasty

\begin{tabular}{|c|c|c|c|c|c|}
\hline Authors \& Year & Study Design & Material & $\begin{array}{c}\text { No. of } \\
\text { Patients }\end{array}$ & $\begin{array}{c}\text { Mean Follow-Up } \\
\text { Duration (mos) }\end{array}$ & Complication \\
\hline Joffe et al., 1999 & prospective & titanium & 148 & 12 & 1 infection $(0.6 \%)$ \\
\hline Blake et al., 1990 & retrospective & titanium & 20 & 52 & no removals $(0 \%)$ \\
\hline Eufinger et al., 1998 & retrospective & titanium & 22 & 24 & 1 infection (4.5\%) \\
\hline Kamyszek et al., 2001 & retrospective & titanium & 76 & 8 & 2 impaired healings (2.6\%) \\
\hline \multirow[t]{4}{*}{ Matsuno et al., 2006} & retrospective & titanium & 77 & 64 & 2 infections (2.6\%) \\
\hline & & PMMA & 58 & & 8 infections (13.8\%) \\
\hline & & autogenous bone & 54 & & 14 infections (25.9\%) \\
\hline & & ceramics (Alumina $+\mathrm{HA}$ ) & 17 & & 1 infection (5.9\%) \\
\hline van Gool, 1985 & retrospective & PMMA & 45 & 39 & 2 removals $(4.4 \%)$ \\
\hline \multirow[t]{3}{*}{ Moreira-Gonzalez et al., 2003} & retrospective & autogenous bone & 312 & 39 & 22 infections/exposure (7\%) \\
\hline & & PMMA & 75 & & 10 infections/exposure (13.3\%) \\
\hline & & $\mathrm{HA}$ & 58 & & 13 infections/exposure (22.4\%) \\
\hline \multirow[t]{2}{*}{ Kriegel et al., 2007} & retrospective & PMMA & 36 & 44 & removal of 2 implants (4.5\%) \\
\hline & & $\begin{array}{l}\text { autologous bone graft } \\
\text { (Tutoplast) }\end{array}$ & 25 & 15 & removal of 2 implants (8\%) \\
\hline Marchac \& Greensmith, 2008 & retrospective & PMMA & 32 & $8.2^{*}$ & 4 removals (12.5\%) \\
\hline Friedmann et al., 200013 & prospective & $\mathrm{HA}$ & 38 & 24 & 3 infections (7.9\%) \\
\hline Costantino et al., 2000 & retrospective & $\mathrm{HA}$ & 21 & 15 & no removal $(0 \%)$ \\
\hline Verheggen \& Merten, 2001 & retrospective & $\mathrm{HA}$ & 11 & 6 & 1 impaired healing (9\%) \\
\hline Durham et al., 2003 & retrospective & $\mathrm{HA}$ & 9 & 11 & 2 infections (22.2\%) \\
\hline Eppley et al., 2003 & retrospective & $\mathrm{HA}$ & 62 & 24 & 3 infections (5\%) \\
\hline Poetker et al., 2004 & retrospective & $\mathrm{HA}$ & 76 & 13 & 2 infections (2.63\%) \\
\hline Saringer et al., 2002 & retrospective & CFRP & 29 & 39 & 0 infections \\
\hline Sanus et al., 2008 & prospective & acrylic resin (Cortoss) & 13 & 24.3 & 0 removals or infections \\
\hline Scolozzi et al., 2007 & case report & PEEK & 1 & 12 & 0 removal \\
\hline
\end{tabular}

* This follow-up duration was reported in years.

1). Nevertheless, it is unclear which material provides the best overall result.

The CAD/CAM titanium plates offer an excellent choice for cranioplasty based on their strength, low infection rate, biocompatibility, handling characteristics, and suitability for postoperative imaging techniques,,, $21-23$ but they are often avoided because of their high costs. However, it may be advisable to take into account that the long-term suitability of this material could compensate its higher production costs. Furthermore, operative time, infection, and revision rates as additional cost factors have to be calculated as well. There are few longterm studies of cranioplastics in the literature. In this long-term follow-up study, we examined 25 patients with large calvarial defects who underwent cranioplasty with titanium plates. We observed these patients for up to 12 years after the procedure, and we reviewed the existing literature focusing especially on complications, removal rates, and long-term follow-up results of cranioplasties.

\section{Methods}

Between 1983 and 2002, 241 patients underwent craniectomy for various reasons in our department. The bone flap was reinserted in 149 cases. Since 1996, CAD/
CAM titanium plates (Fig. 1) have been inserted for a variety of large skull defects (Table 2).

Between 1996 and 2002, 26 patients (15 men and 11 women) underwent cranioplasty with $\mathrm{CAD} / \mathrm{CAM}$ titanium implants (Cranio Construct; Bochum $\mathrm{GmbH}$ ) due to a posttraumatic nonrestorable large skull defect, lysis, or infection of the bone flap after severe head trauma (13 patients); cerebral infarction (5 patients); meningioma (4 patients); and dysplasia, bone erosion as a result of a growing arachnoidal cyst, herpes encephalitis, and brain abscess (1 patient each). In 6 of these patients 2 plates were implanted. One patient underwent bilateral cranioplasty with titanium (Fig. 2). Four patients underwent bifrontal cranioplasty (Figs. 3 and 4).

The titanium implant was inserted after exposure of the margins of the skull defect without opening the dura mater. If necessary, plate insertion was supported by hyperventilation or lumbar CSF drainage for several minutes. Central dural tenting sutures were placed routinely. Between 1996 and 1998, the fastening of the plates was performed with titanium miniplates from various companies. Since 1998, CranioFix titanium clamps (Aesculap AG) have been used to fasten the plates. A wound drain was placed for 3 days in all cases.

The size of the skull defects and plates ranged from 


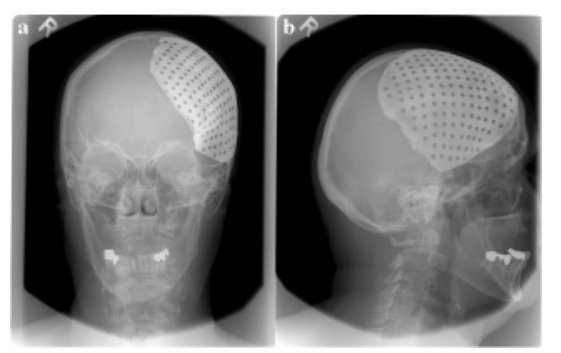

FIG. 1. Anteroposterior (a) and lateral (b) radiographs obtained in a patient following frontotemporoparietal craniectomy for decompression.

65 to $155 \mathrm{~mm}$ (mean $112 \mathrm{~mm}$ ). The patients' age at operation ranged from 6 to 63 years (mean 35.6 years), and the follow-up period ranged from 6 to 12 years (mean 8.1 years). The span of time between the removal of the bone flap and the insertion of the CAD/CAM titanium plate ranged from 2 to 14 months (mean 6.5 months).

The follow-up examination included a questionnaire covering subjectively experienced pain and satisfaction with the cosmetic result based on two 100-mm-long VASs: the VASPI and VASC. Overall satisfaction with cranioplasty as a whole was evaluated using the Odom criteria. Furthermore, eventual changes in the quality of life after cranioplasty were evaluated, and the patients were asked if they would have chosen cranioplasty again. Postoperative CT scanning was routinely performed.

One patient died of a heart attack 6 years after plate insertion and was lost to the last follow-up. At the 1-year follow-up, this patient reported no specific complaints, but he did not fill out the questionnaire. Therefore, a total of 25 patients were evaluated.

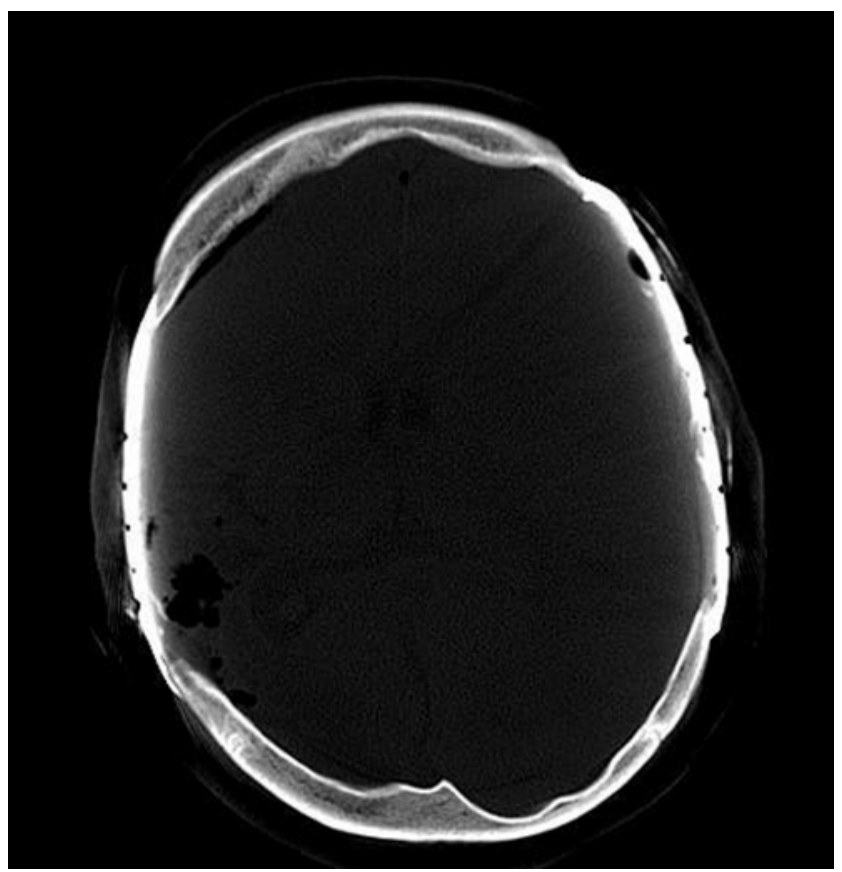

FIG. 2. Axial CT scan obtained in a 13-year-old girl with the history of a severe head injury and subsequent bilateral osteolysis with the need of bilateral alloplastic cranioplasty.
TABLE 2: Localization, side, and reasons of autologous bone flap loss in 26 patients

\begin{tabular}{lc}
\hline \multicolumn{1}{c}{ Localization } & No. of Patients \\
\hline frontal & 16 \\
frontotemporoparietal & 4 \\
bifrontal & 3 \\
frontal & 1 \\
frontoparietal & 2 \\
temporal & \\
side & 10 \\
It & 11 \\
rt & 4 \\
bifrontal & 1 \\
bilat & \\
reason for bone flap loss & 14 \\
infection & 8 \\
lysis & 2 \\
nonrestorable trauma & 1 \\
bone erosion & 1 \\
dysplasia &
\end{tabular}

\section{Results}

Analysis of the Odom criteria showed that $68 \%$ of the patients (17 of 25) noted excellent, 24\% (6 of 25) good, $0.8 \%$ ( 2 of 25) fair, and $0 \%$ poor results. Overall, $84 \%$ (21 of 25) did not suffer any pain, and $88 \%$ (22 of 25) were satisfied with the cosmetic result of titanium cranioplasty with a score of $>75 \mathrm{~mm}$ on the VASC (Fig. 5).

Only 2 female patients, one with a history of a severe head injury and the other with a left brain infarction suffered pain periodically with an intensity of 48 and $61 \mathrm{~mm}$ on the VASPI, respectively. The patient with the left brain infarction was dissatisfied with the cosmetic result and scored $43 \mathrm{~mm}$ on the VASC.

Another female patient with a history of left brain infarction noted a suboptimal cosmetic result and scored $51 \mathrm{~mm}$ on the VASC, but suffered no pain. One patient scored $71 \mathrm{~mm}$ on the VASC. Clinical evaluation and imaging did not reveal any objective reasons for impaired cosmetic results such as asymmetry, swelling, or ill fitting of the plates in these cases. All patients would have chosen to undergo cranioplasty again, noting a considerable improvement in their quality of life following calvarial reconstruction.

Despite artifacts, follow-up imaging of the 4 patients undergoing removal of meningiomas was possible. Nevertheless, the quality of follow-up images in these patients was regarded as suboptimal. Imaging quality was acceptable in the follow-up of the other cases. Extraaxial collections without midline shift were seen on postoperative CT scans in 4 cases, but no surgical intervention was required in the clinically unaffected patients.

The operation time ranged from 60 to 219 minutes (mean 118 minutes). The costs for the titanium plates, including instances in which 2 plates were used, ranged from $€ 2500$ to $€ 5050$ (mean $€ 3733$ ). 


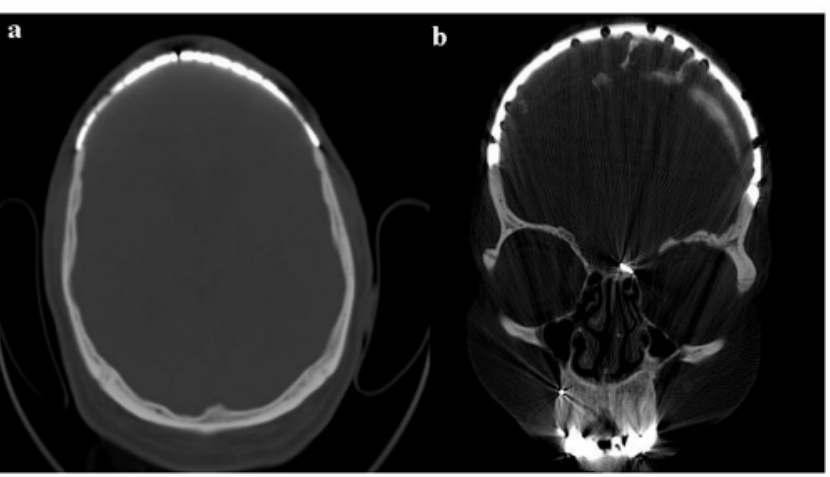

FIG. 3. Axial (a) and coronal (b) CT reconstructions obtained in a 62-year-old patient with the history of a severe head injury and frontobasal fractures with a subsequent infection of the bifrontal bone flap.

None of the implanted titanium plates had to be removed. Due to a postoperative hypertrophy of the temporal muscle and a resulting asymmetry of the face 4 months after insertion of the titanium plate, a reduction of the temporalis muscle was performed in 1 case. In this case, a transient palsy of the frontal ramus of the facial nerve occurred postoperatively.

\section{Discussion}

We presented a long-term follow-up study of 26 patients after placement of CAD/CAM titanium for cranioplasty. None of the plates had to be removed, and almost $90 \%$ of the patients were satisfied with the cosmetic result and overall outcome. The cosmetic and overall outcomes of our patients did not differ substantially from other studies dealing with CAD/CAM implants, but we focused on long-term results, patients' satisfaction, and quality of life. Cranioplasty is the surgical correction of skull defects and has 2 main purposes: protection of the brain and a satisfying cosmetic result. Furthermore, cranioplasty affects cerebral metabolism positively and may facilitate patient rehabilitation. ${ }^{45,46}$

Because of issues of immunocompatibility, a patient's own bone flap is considered the material of choice for a cranioplasty, and we support this point of view. If the bone flap is lost to osteolysis or infection, autologous bone from other parts of the body is rarely used for calvarial reconstruction because of donor site morbidity and shaping problems. In these cases alloplastic implants are more frequently used. The decision for one of the many available materials often depends on the surgeon's preference and experience as well as costs and availability of modeling techniques. The most frequently used cranioplasty materials are PMMA, HA, and titanium.

Because of its good biocompatibility and low costs, PMMA is the most frequently used alloplastic material and is still regarded as the material of choice by many authors. ${ }^{26,29}$ Nonetheless, depending on anatomical conditions as well as the size and shape of the skull defect, intraoperative modeling can be time-consuming and difficult. The disadvantage of inappropriate modeling especially in large skull defects and sensitive cosmetic regions has been solved by the CAD technique, which can be used for PMMA with good results. The CAD/CAM PMMA implants are an acceptable choice even in poorer regions of the world. ${ }^{9,18}$ Recently, bioactive composite materials consisting of acrylic resins gained access into calvarial reconstruction with good results. ${ }^{38}$

Hydroxyapatite is probably the most frequently used ceramic and is increasingly used in reconstructive surgery. It is the principal component of bone, has the advantage of osteoconductivity, and allows osteointegration. ${ }^{6,25}$ Despite high biocompatibility, inflammatory reactions have been described in numerous studies conducted in

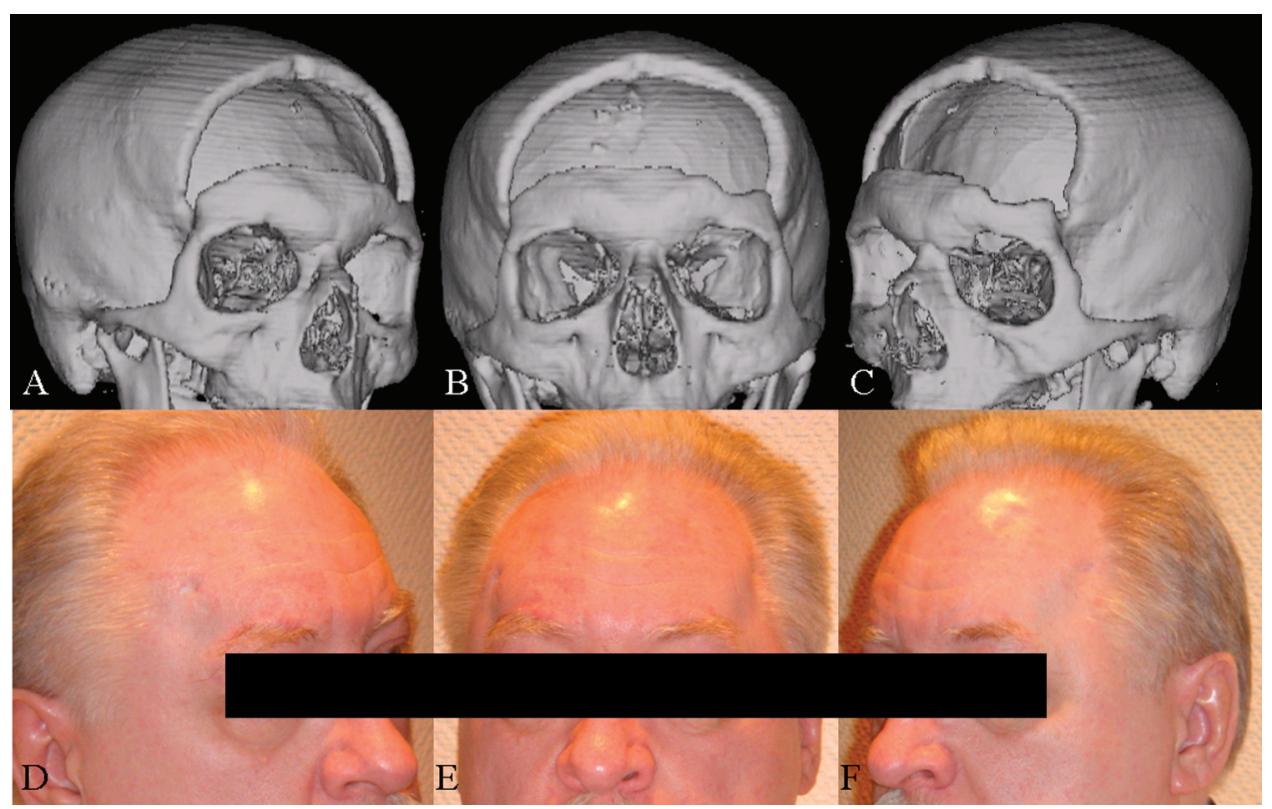

FIG. 4. Preoperative CT reconstructions $(A-C)$ and postoperative photographs $(D-F)$ obtained in a 53-year-old patient with the history of a meningioma and subsequent osteolysis of the bifrontal bone flap in left oblique ( $A$ and $D)$, frontal $(B$ and $E)$, and right oblique ( $\mathrm{C}$ and $\mathrm{F}$ ) views. 


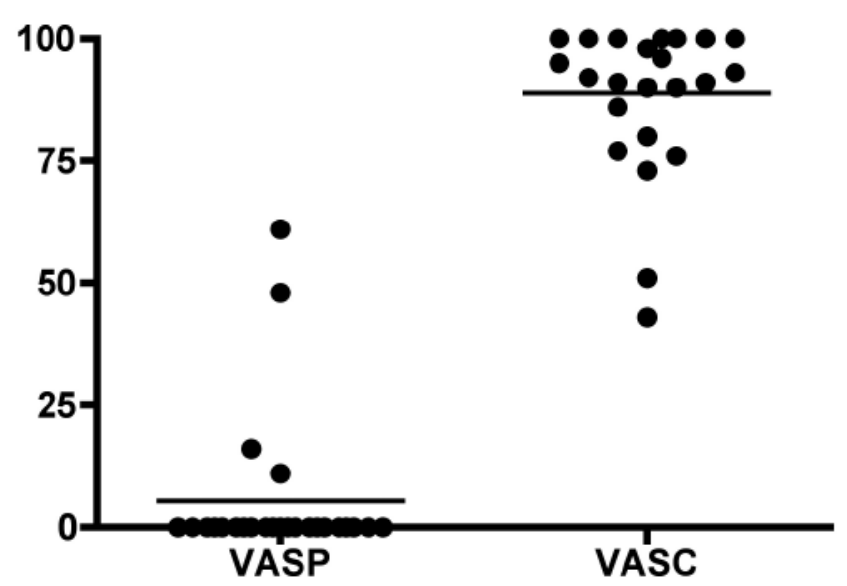

FIG. 5. Graph showing the clinical results according to the VASPI and VASC.

the early postoperative period and the few months after surgery. Thus, some authors have regarded HA as a contraindication for craniofacial reconstruction and pediatric populations in special settings. ${ }^{6,13,15,27,29}$ Costantino et al. ${ }^{6}$ managed to attain a $0 \%$ infection/removal rate, but their small collective comprised mostly patients with small skull defects that occurred after the suboccipital lateral approach for vestibular schwannomas. Furthermore, the costs of HA and other ceramic CAD/CAM implants exceed even CAD/CAM titanium implants. ${ }^{8}$

Carbon and PEEK are other biocompatible materials that provide high strength and radiolucency for postoperative imaging. They have been put to use particularly in orthopedic and spinal surgery with good clinical and radiographic results. ${ }^{3}$ In a series of 29 patients, not a single CFRP plate had to be removed. ${ }^{39}$ The CAD/CAM PEEK implants for cranioplasty are gaining access in calvarial reconstruction, ${ }^{42}$ but larger case studies have not yet been reported in the literature.

Bioactive materials are gaining greater importance and exhibit superior characteristics to classic allografts in biomechanical studies and small clinical short-term settings, ${ }^{35,38}$ but they still have to stand the test of time. Osteoconductive bioresorbable materials, tissue engineering, ${ }^{36,37,40,41}$ osteoinduction by growth factors, and gene therapy ${ }^{12,17,31}$ are only recently gaining access in larger clinical settings. While there are studies in which authors have preferred PMMA or HA as the optimal material for cranioplasty, titanium plates offer a good choice for cranioplasty based on their strength, biocompatibility, handling characteristics, and suitability for postoperative imaging techniques, ${ }^{5,21-23}$

While materials such as PMMA and HA show biocompatible and osteoconductive characteristics without significant toxic and immunogenic properties, 4-13.8\% of PMMA plates ${ }^{26,43}$ and $2.6-10 \%$ of HA-based implants need replacing. ${ }^{10,11,44}$ The best HA series with a complication rate of $<2.6 \%$ involved only cranioplasties $<6 \mathrm{~cm}$ following a retrosigmoid approach in most cases. ${ }^{34}$ In a small series of 9 patients undergoing large skull defect reconstruction, $22 \%$ of HA-based ceramics had to be removed because of infections. ${ }^{8}$ The infection rate of tita- nium implants including large skull defects ranges from 0 to $4.5 \% .^{2,11,21,23}$ An often-cited reason for the removal of HA and PMMA implants is the proximity to the sinuses, a problem that exists for cranioplasty with titanium as well. In our own study, the frontal sinus was involved in 6 cases.

The costs of large ceramic plates amount to $\sim \$ 7000,{ }^{8}$ while the costs of large titanium CAD/CAM implants range from $€ 2050$ to $5000^{11}$ and are thus comparable in cost to the CAD/CAM implants used in our series. As patients requiring alloplastic cranioplasty have often already undergone multiple operative procedures, one has to question whether titanium CAD/CAM cranioplasty is actually more expensive than PMMA cranioplasty. In our view, this statement does not take into account the more frequent revision surgery due to higher complication rates of PMMA and the resulting costs. Furthermore, results from clinical series with HA cranioplasty show higher complication rates and higher production costs than titanium cranioplasty.

The suboptimal results of imaging quality due to titanium artifacts for follow-up of the meningiomas in our study cannot be denied. Nevertheless, imaging quality was acceptable in the follow-up of the other cases.

\section{Conclusions}

With the aid of CAD technology, all of the currently used alloplastic materials are good choices even for large skull defect cranioplasty. Cranioplasty with CAD/CAM titanium plates is suitable for calvarial reconstruction of all sizes, providing the lowest complication rate, reasonable costs when regarding complications and removal rates over long-term periods, and the possibility of acceptable postoperative imaging. Analyzing our data and the literature, we have come to the conclusion that due to its costs and availability, PMMA is suitable for patients requiring primary cranioplasty or long-term follow-up imaging of tumors. Titanium implants seem to be the material of choice in cases of secondary cranioplasty of large skull defects resulting from decompressive craniectomy after trauma or infarction. Expensive ceramics that are gaining larger access into reconstructive calvarial surgery show no obvious advantage over titanium or PMMA.

\section{Disclaimer}

The authors report no conflict of interest concerning the materials or methods used in this study or the findings specified in this paper.

\section{Acknowledgment}

The authors thank Mrs. Leah Hecker for technical support.

\section{References}

1. Auguste KI, McDermott MW: Salvage of infected craniotomy bone flaps with the wash-in, wash-out indwelling antibiotic irrigation system. Technical note and case series of 12 patients. J Neurosurg 105:640-644, 2006

2. Blake GB, MacFarlane MR, Hinton JW: Titanium in reconstructive surgery of the skull and face. Br J Plast Surg 43:528-535, 1990 
3. Brantigan JW, Steffee AD: A carbon fiber implant to aid interbody lumbar fusion - two year clinical results in the first 26 patients. Spine 18:2106-2117, 1993

4. Bruce JN, Bruce SS: Preservation of bone flaps in patients with postcraniotomy infections. J Neurosurg 98:1203-1207, 2003

5. Chandler CL, Uttley D, Archer DJ, MacVicar D: Imaging after titanium cranioplasty. Br J Neurosurg 8:409-414, 1994

6. Costantino PD, Chaplin JM, Wolpoe ME, Catalano PJ, Sen $\mathrm{C}$, Bederson JB, et al: Applications of fast-setting hydroxyapatite cement: cranioplasty. Otolaryngol Head Neck Surg 123:409-412, 2000

7. Dean D, Min KJ, Bond A: Computer aided design of largeformat prefabricated crania plates. J Craniofac Surg 14:819832,2003

8. Durham SR, McComb JG, Levy ML: Correction of large (>25 $\mathrm{cm}^{2}$ ) cranial defects with "reinforced" hydroxyapatite cement: technique and complications. Neurosurgery 52:842-845, 2003

9. D'Urso PS, R Atkinson L, Lanigan MW, Earwaker WJ, Bruce IJ, Holmes A, et al: Stereolithographic (SL) biomodelling in craniofacial surgery. Br J Plast Surg 51:522-530, 1998

10. Eppley BL, Hollier L, Stal S: Hydroxyapatite cranioplasty: 2. Clinical experience with a new quick-setting material. J Craniofac Surg 14:209-214, 2003

11. Eufinger $\mathrm{H}$, Wehmoller M: Individual prefabricated titanium implants in reconstructive craniofacial surgery: clinical and technical aspects of the first 22 cases. Plast Reconstr Surg 102:300-308, 1998

12. Feinberg SE, Hollister SJ, Halloran JW, Chu TM, Krebsbach PH: Image-based biomimetic approach to reconstruction of the temporomandibular joint. Cells Tissues Organs 169:309-321, 2001

13. Friedman CD, Costantino PD, Synderman CH, Chow LC, Takagi S: Reconstruction of the frontal sinus and frontofacial skeleton with hydroxyapatite cement. Arch Facial Plast Surg 2:124-129, 2000

14. Gladstone HB, McDermott MW, Cooke DD: Implants for cranioplasty. Otolaryngol Clin North Am 28:381-400, 1995

15. Gosain AK, Persing JA: Biomaterials in the face: benefits and risks. J Craniofac Surg 10:404-414, 1999

16. Grant GA, Jolley M, Ellenbogen RG, Roberts TS, Gruss JR, Loeser JD: Failure of autologous bone-assisted cranioplasty following decompressive craniectomy in children and adolescents. J Neurosurg 100 (2 Suppl Pediatrics):163-168, 2004

17. Green D, Walsh D, Mann S, Oreffo RO: The potential of biomimesis in bone tissue engineering: lessons from the design and synthesis of invertebrate skeletons. Bone 30:810-815, 2002

18. Hieu LC, Bohez E, Vander Sloten J, Oris P, Phien HN, Vatcharaporn E, et al: Design and manufacturing of cranioplasty implants by 3 -axis cnc milling. Technol Health Care 10:413-423, 2002

19. Jagannathan J, Okonkwo DO, Dumont AS, Ahmed H, Bahari A, Prevedello DM, et al: Outcome following decompressive craniectomy in children with severe traumatic brain injury: a 10-year single-center experience with long-term follow up. $\mathbf{J}$ Neurosurg 106 (4 Suppl):268-275, 2007

20. Jho DH, Neckrysh S, Hardman J, Charbel FT, Amin-Hanjani S: Ethylene oxide gas sterilization: a simple technique for storing explanted skull bone. Technical note. J Neurosurg 107:440-445, 2007

21. Joffe J, Harris M, Kahugu F, Nicoll S, Linney A, Richards R: A prospective study of computer-aided design and manufacture of titanium plate for cranioplasty and its clinical outcome. $\mathbf{B r}$ J Neurosurg 13:576-580, 1999

22. Joffe JM, McDermott PJ, Linney AD, Mosse CA, Harris M: Computer-generated titanium cranioplasty: report of a new technique for repairing skull defects. Br J Neurosurg 6:343350, 1992

23. Kamyszek T, Weihe S, Scholz M, Wehmöller M, Eufinger H: Versorgung kraniofazialer Knochendefekte mit individuell vorgefertigten Titanimplantaten. Mund Kiefer Gesichtschir 5:233-238, 2001

24. Kriegel RJ, Schaller C, Clusmann H: Cranioplasty for large skull defects with PMMA (polymethylmethacrylate) or Tutoplast processed autogenic bone grafts. Zentralbl Neurochir 68:182-189, 2007

25. Maas CS, Merwin GE, Wilson J, Frey MD, Maves MD: Comparison of biomaterials for facial bone augmentation. Arch Otolaryngol Head Neck Surg 116:551-556, 1990

26. Marchac D, Greensmith A: Long-term experience with methylmethacrylate cranioplasty in craniofacial surgery. J Plast Reconstr Aesthet Surg 61:744-752, 2008

27. Matic D, Phillips JH: A contraindication for the use of hydroxyapatite cement in the pediatric population. Plast Reconstr Surg 110:1-5, 2002

28. Matsuno A, Tanaka H, Iwamuro H, Takanashi S, Miyawaki S, Nakashima M, et al: Analyses of the factors influencing bone graft infection after delayed cranioplasty. Acta Neurochir (Wien) 148:535-540, 2006

29. Moreira-Gonzalez A, Jackson IT, Miyawaki T, Baqrakat K, DiNick V: Clinical outcome in cranioplasty: critical review in long-term follow-up. J Craniofac Surg 14:144-153, 2003

30. Morgalla MH, Will BE, Roser F, Tatagiba M: Do long-term results justify decompressive craniectomy after severe traumatic brain injury? J Neurosurg 109:685-690, 2008

31. Oreffo RO, Triffitt JT: Future potentials for using osteogenic stem cells and biomaterials in orthopedics. Bone 25 (2 Suppl):5S-9S, 1999

32. Park HK, Dujovny M, Agner C, Diaz FG: Biomechanical properties of calvarium prosthesis. Neurol Res 23:267-276, 2001

33. Park J, Kim E, Kim GJ, Hur YK, Guthikonda M: External decompressive craniectomy including resection of temporal muscle and fascia in malignant hemispheric infarction. $\mathbf{J}$ Neurosurg [epub ahead of print], 2008

34. Poetker DM, Pytynia KB, Meyer GA, Wackym PA: Complication rate of transtemporal hydroxyapatite cement cranioplasties: a case series review of 76 cranioplasties. Otol Neurotol 25:604-609, 2004

35. Pomrink GJ, DiCicco MP, Clineff TD, Erbe EM: Evaluation of the reaction kinetics of CORTOSS, a thermoset cortical bone void filler. Biomaterials 24:1023-1031, 2003

36. Quarto R, Mastrogiacomo M, Cancedda R, Kutepov SM, Mukhachev V, Lavroukov A, et al: Repair of large bone defects with the use of autologous bone marrow stromal cells. $\mathbf{N}$ Engl J Med 344:385-386, 2001

37. Rohner D, Hutmacher DW, See P, Tan KC, Yeow V, Tan SY, et al: Individually CAD-CAM technique designed, bioresorbable 3-dimensional polycaprolactone framework for experimental reconstruction of craniofacial defects in the pig. Mund Kiefer Gesichtschir 6:162-167, 2002

38. Sanus GZ, Tanriverdi T, Ulu MO, Kafadar AM, Tanriover N, Ozlen F: Use of Cortoss as an alternative material in calvarial defects: the first clinical results in cranioplasty. J Craniofac Surg 19:88-95, 2008

39. Saringer W, Nobauer-Huhmann I, Knosp E: Cranioplasty with individual carbon fibre reinforced polymere (CFRP) medical grade implants based on CAD/CAM technique. Acta Neurochir (Wien) 144:1193-1203, 2002

40. Schantz JT, Hutmacher DW, Lam CX, Brinkmann M, Wong KM, Lim TC, et al: Repair of calvarial defects with customised tissue-engineered bone grafts II. Evaluation of cellular efficiency and efficacy in vivo. Tissue Eng 9 (Suppl 1):S127-S139, 2003

41. Schantz JT, Teoh SH, Lim TC, Endres M, Lam CX, Hut- 


\section{Large skull defect cranioplasty}

macher DW: Repair of calvarial defects with customized tissue-engineered bone grafts I. Evaluation of osteogenesis in a three-dimensional culture system. Tissue Eng 9 (Suppl 1):S113-S126, 2003

42. Scolozzi P, Martinez A, Jaques B: Complex orbito-fronto-temporal reconstruction using computer-designed PEEK implant. J Craniofac Surg 18:224-228, 2007

43. van Gool AV: Preformed polymethylmethacrylate cranioplasties: report of 45 cases. J Maxillofac Surg 13:2-8, 1985

44. Verheggen R, Merten HA: Correction of skull defects using hydroxyapatite cement (HAC)-evidence derived from animal experiment and clinical experience. Acta Neurochir (Wien) 143:919-926, 2001

45. Winkler PA, Stummer W, Linke R, Krishnan KG, Tatsch K: Influence of cranioplasty on postural blood flow regulation, cerebrovascular reserve capacity, and cerebral glucose metabolism. J Neurosurg 93:53-61, 2000
46. Yoshida K, Furuse M, Izawa A, Iizima N, Kuchiwaki H, Inao $\mathrm{S}$ : Dynamics of cerebral blood flow and metabolism in patients with cranioplasty as evaluated by $133 \mathrm{Xe}$ CT and 31P magnetic resonance spectroscopy. J Neurol Neurosurg Psychiatry 61:166-171, 1996

Manuscript submitted January 2, 2009.

Accepted March 27, 2009.

Address correspondence to: Mario Cabraja, M.D., Department of Neurosurgery, Charité-Universitätsmedizin Berlin, Campus Virchow-Klinikum, Augustenburger Platz 1, 13353 Berlin, Germany. email: mario.cabraja@charite.de. 